\title{
DATE NOI PRIVIND DIVERSITATEA FAUNEI ECOSISTEMELOR ACVA-PALUSTE ALE LACULUI CAHUL
}

\section{Bușmachiu Galina, Nistreanu Victoria, Țurcan V., Munjiu Oxana}

Institutul de Zoologie, 2028 Chișinău, R. Moldova

bushmakiu@yahoo.com, vicnistreanu@gmail.com

https://doi.org/10.53937/9789975315975.32

Bazinul fluviului Dunărea reprezintă doar o mică parte din teritoriul Republicii Moldova, lungimea căruia este doar 480 de metri, dar include și o serie de râuri și pâraie, adesea parțial secate, și câteva lacuri, dintre care cel mai mare este Lacul Cahul, care comunică cu Dunărea printr-un canal. De la nord spre lac curge râul Cahul, care pentru cea mai mare parte a anului este superficial, și numai în timpul ploios se umple cu apă.

Lacul Cahul este localizat în unitatea teritorială autonomă Găgăuzia,

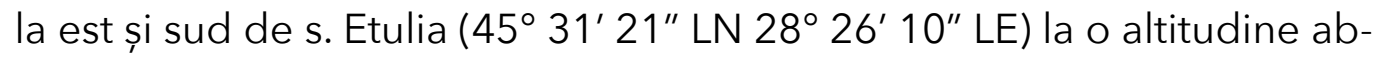
solută de 2-115 m. Zona este amplasată la limita de sud, la 170 km spre sud de mun. Chișinău, în limitele câmpiei Cahul. Principalele tipuri de ecosisteme sunt acvatice, palustre și luncile inundabile.

Nevertebrate. Ca rezultat al investigațiilor efectuate în zona adiacentă lacului au fost identificate 33 specii de nevertebrate din 4 clase: Collembola, Insecta, Bivalvia și Gastropoda.

Clasa Collembola a fost reprezentată de 19 specii: Schoettella ununguiculata (Tullberg, 1869), Xenylla maritima Tullberg, 1869, Friesea mirabilis (Tullberg, 1871), Mesaphorura critica Ellis, 1976, M. macrochaeta Rusek, 1976, Protaphorura armata (Tullberg, 1869), P. cancellata (Gisin, 1956), P. fimata (Gisin, 1952), Isotoma viridis Bourlet, 1839, Proisotomina bipunctata (Axelson, 1903), Folsomides parvulus (Stach, 1922), Hemisotoma thermophila (Axelson, 1900), Parisotoma notabilis (Schäffer, 1896), Entomobrya marginata Tullberg, 1871, Orchesella albofasciata Stach, 1960, Lepidocyrtus paradoxus Uzel, 1890, L. cyaneus Tullberg, 1871 L. violaceus (Lubbock, 1873) și Pseudosinella sexoculata (Schott 1902). 
Dintre insecte au fost identificate 4 specii din ordinul Odonata: Ishnura elegans (Vander Linden, 1820), Sympetrum sanguineum (Linnaeus, 1758), Orthetrum cancellatum Linnaeus, 1758, Lestes barbarus (Fabricius, 1798) și 5 specii din ordinul Lepidoptera: Argynnis pandora Denis et Schiffermüller, 1775, Vanessa atalanta (Linnaeus, 1758), Colias hyale (Linnaeus, 1758), Papilio machaon Linnaeus, 1758, Iphiclides podalirius (Linnaeus, 1758).

Moluștele au fost reprezentate de 2 specii din clasa Bivalvia: Unio tumidus (Philipson, 1788) și Sinanodonta woodiana (I.Lea, 1834) și 3 specii din clasa Gastropoda: Viviparus viviparus (Linnaeus, 1758), Viviparus contectus (Millet, 1813) și Planorbarius corneus (Linnaeus, 1758).

Din speciile de nevertebrate putem remarca prezența fluturelui Papilio machaon Linnaeus, 1758 care este inclus în Cartea Roșie a Republicii Moldova.

Conform datelor din literatură (Andreev et al., 2012) în zona dată sunt citate speciile de Bivalvia: Anodonta cygnea (Linnaeus, 1758) și Sphaerium corneum (Linnaeus, 1758), Gastropoda: Lymnaea truncatula (O. F. Müller, 1774), Dolabella auricularia (Lightfoot, 1786), Viviparus contectus (Millet, 1813) și Planorbis planorbis (Linnaeus, 1758). Dintre lipitori sunt menționate atât Haemopis sanguisuga (Linnaeus, 1758), cât și specia rar depistată în Republica Moldova Hirudo medicinalis Linnaeus, 1758. Este de remarcat faptul că nu sunt date bibliografice referitor la diversitatea insectelor din zona lacului Cahul.

Vertebrate terestre. Pe parcursul cercetărilor au fost identificate specii din toate grupurile taxonomice de vertebrate terestre. Dintre amfibieni au fost semnalate 8 specii: tritonul comun (Triturus vulgaris), cel crestat ( $T$. cristatus), broasca râioasă verde (Bufo viridis), izvorașul cu abdomen galben (Bombina bombina), broasca mare de lac (Rana ridibunda), broasca mică de lac ( $R$. lessonae), brotăcelul (Hyla arborea) și broasca săpătoare brună (Pelobates fuscus).

Reptilele au fost reprezentate de țestoasa de baltă (Emys orbicularis), 
șopârla verde (Lacerta viridis) și ageră (L.agilis), șopârla de iarbă (Podarcis taurica), șarpele de casă (Natrix natrix), șarpele de apă (N. tesselata), șarpele cu abdomen galben (Coluber caspius) și șarpele de alun (Coronella austriaca).

Cea mai bogată și bine reprezentată a fost avifauna - cu peste 20 specii, în special speciile acvatice și de baltă: pelican comun (Pelecanus onochrotalus) -a fost observat un stol de cca 200 indivizi zburând deasupra lacului, cormoran (Phalacrocorax carbo), corcodel mare (Podiceps cristatus), stârc pitic (Ixobricgus minutus), egretă mare (Casmerodius albus), stârc cenușiu (Ardea cinerea), barza albă (Ciconia ciconia), lebădă de vară (Cygnus olor), gârlița mare (Anser albifrons), rața mare (Anas platyrhynchos), rață cârâitoare (A. querquedula), lișiță (Fulica atra), pociorong (Himantopus himantopus), nagâț (Vanellus vanellus), pescăruș râzător (Larus ridibundus), chira de baltă (Sterna hirundo), chrighița cu obraz alb (Chlidonias hybridus), chirighița neagră (Ch. niger), erete de stuf (Circus aeruginosus) și altele. Conform datelor existente 44 specii de păsări cuibăresc pe acest teritoriu, 14 specii sunt oaspeţi de vară și 31 specii sunt cunoscute ca migratoare (Andreev et al., 2012).

Mamiferele au fost reprezentate de arici, cârtiță, chițcan comun, chițcan mic, chițcan de câmp, liliacul de apă, liliacul de iaz, liliacul cu aripi late, șobolanul de apă, ondatra, 6 specii de rozătoare mici, vidra, vulpea.

Lacul Cahul și teritoriile adiacente prezintă o importanță deosebită în conservarea biodiversității din zona de sud a republicii, iar cercetările vor fi continuate.

Studiile au fost efectuate în cadrul proiectelor fundamentale 11.817.08.13F, 15.187.0211F și aplicativ 15.817.02.27A realizate la Institutul de Zoologie. 